\title{
THE RESONANT HALF BRIDGE DUAL CONVERTER WITH A RESONANT GATE DRIVE
}

\author{
Quan Li and Peter Wolfs
}

Central Queensland University

\begin{abstract}
The resonant half bridge dual converter, which is suitable for the photovoltaic Module Integrated Converter (MIC), has been previously developed. The 100-Watt converter has achieved a reasonable efficiency under a $1 \mathrm{MHz}$ switching frequency. However at these frequencies the power required to drive the mosfets becomes a major part of the total power loss of the resonant converter. The power dissipates as heat in the drive circuit and significantly reduces the efficiency of the converter. This paper studies a resonant transition mosfet gate drive circuit for the half bridge dual converter, which ideally has zero power loss. The operation of the resonant gate drive circuit is explained. Both of the simulation and experimental results are provided to verify the theoretical analysis.
\end{abstract}

\section{INTRODUCTION}

The resonant half bridge dual converter shown in Figure 1 has been developed for a $100 \mathrm{~W}$ DC-DC conversion stage in the photovoltaic Module Integrated Converter (MIC), [1]. The resonant half bridge dual converter is a Zero-Voltage Switching (ZVS) Quasi-Resonant Converter (QRC) and completely removes the main device switching loss. However, higher current and voltage stresses exist due to the resonant feature and this leads to higher conduction loss. This must be minimized in order not to cancel the reduction in the switching loss and mosfets with low on resistances are desirable. Because the mosfet die size must be larger, the input capacitances tend to be large, [2]. This requires high gate charge from the drive circuit and the energy dissipates as heat in the conventional drivers. This is exacerbated when the switching frequency is high as the power dissipation is proportional to the switching frequency. Experimental measurements on MAX4429 drivers in a resonant half bridge dual converter with 1 $\mathrm{MHz}$ converter switching frequency or $500 \mathrm{kHz}$ device switching frequency, showed total gate losses of $3.5 \mathrm{~W}$ [3]. This is significant in a 100-Watt converter and reduces the efficiency.

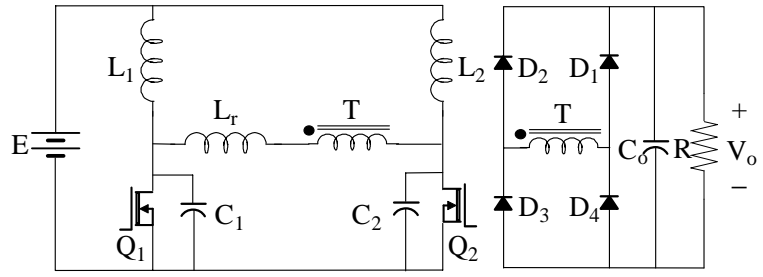

Figure 1. Resonant Half Bridge Dual Converter

In order to reduce the power consumption in the mosfet gate drive circuit, resonant technology can be used. This paper introduces a new resonant transition gate drive circuit for the half bridge dual converter. This resonant gate drive circuit employs only one small inductor in addition to the conventional gate drive circuit and has ideally zero power loss. The operation of the new drive circuit is studied in detail. Both of the simulation and experimental results are provided to verify the theoretical analysis. The experiment presents a significant power reduction in the resonant transition gate drive circuit.

\section{CONVENTIONAL MOSFET GATE DRIVE CIRCUIT}

The conventional mosfet gate drive circuit is readily available as integrated semiconductor chips. These integrated mosfet drivers commonly employ two transistors in the totem-pole arrangement as shown in Figure 2.

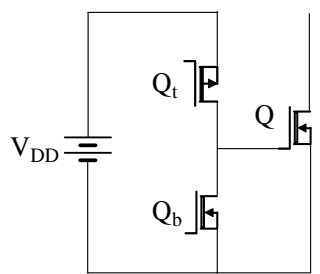

Figure 2. Conventional Mosfet Drive Circuit

While the conventional mosfet driver is easy to use and has a compact package, it is subject to the following power loss mechanisms, [4]:

- $C V^{2}$ loss, which is caused by the mosfet gate capacitance charging and discharging current flowing through the on resistances of $\mathrm{Q}_{t}$ and $\mathrm{Q}_{\mathrm{b}}$.

- Cross conduction loss, which results from shorting the supply voltage across $\mathrm{Q}_{\mathrm{t}}$ and $\mathrm{Q}_{\mathrm{b}}$ if the closings of the two transistors are overlapped to any degree.

- Switching loss, which is due to the hard switching conditions of $\mathrm{Q}_{t}$ and $\mathrm{Q}_{\mathrm{b}}$.

Among these power losses, $C V^{2}$ loss is the dominant part. It is independent of the gate charge rate and will not reduce with shorter gate charging times. 


\section{THE RESONANT TRANSITION GATE DRIVE CIRCUIT}

To reduce driving losses, different types of the resonant gate drive circuits have been proposed, [4][11]. In [4]-[6], higher than normal charging or discharging currents due to the resonant effect flow through the transistors in the drive circuit and the conduction loss is still high. In [7]-[9], the power loss of the drive circuit cannot be minimized as transistors in the gate drive circuit still switch with hardswitching conditions. In [10][11], an ideally lossless gate drive circuit was proposed as shown in Figure 3. Both of the turn on and the turn off are achieved by using a small inductor to provide current to charge and discharge the input capacitance of the mosfet during a transition time when neither gate driver transistors conduct. A capacitor $\mathrm{C}$, is required to maintain a DC level equal to the average gate voltage.

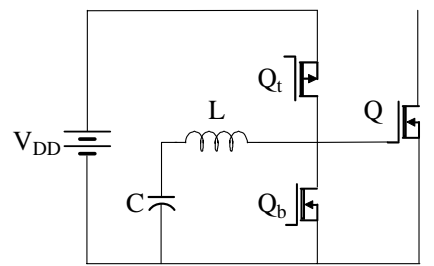

Figure 3. Resonant Transition Gate Drive in [10][11]

Figure 4 shows the resonant transition gate drive circuit for the resonant half bridge dual converter. Compared with the conventional mosfet gate drive circuit, only one small inductor $\mathrm{L}_{\mathrm{G}}$ is introduced between the gates of two power mosfets $\mathrm{Q}_{1}$ and $\mathrm{Q}_{2}$. The anti-phase operation of the gates allows the inductor to be shared and the DC level setting capacitors to be removed.

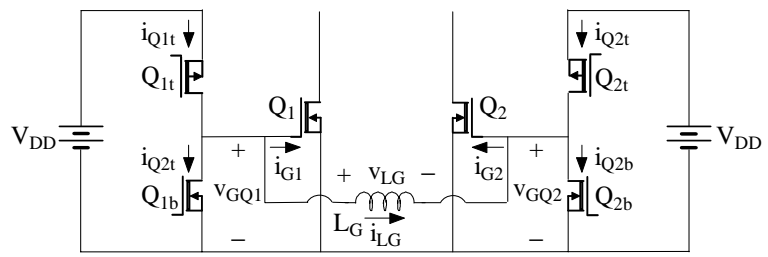

Figure 4. Resonant Transition Gate Drive

The power loss reduction is obtained at the cost of more complex control circuity compared with the conventional mosfet driver. The operation of the resonant transition gate drive circuit can be explained using the waveforms shown in Figure 5.

The inductor current can be approximated as a constant during the overlapping conduction period of the mosfets $\mathrm{Q}_{1}$ and $\mathrm{Q}_{2}$ as this period is relatively short compared with the switching period $\mathrm{T}_{\mathrm{s}}$. Within the time interval marked as $T_{d 1}$, the gate capacitance of $Q_{2}$ is charged. The gate capacitance of $Q_{1}$ is later discharged over a period of the same length. Therefore the energy is transferred back and forth between two mosfet gate capacitances. Theoretically, the resonant gate drive circuit has zero power loss due to the following features:

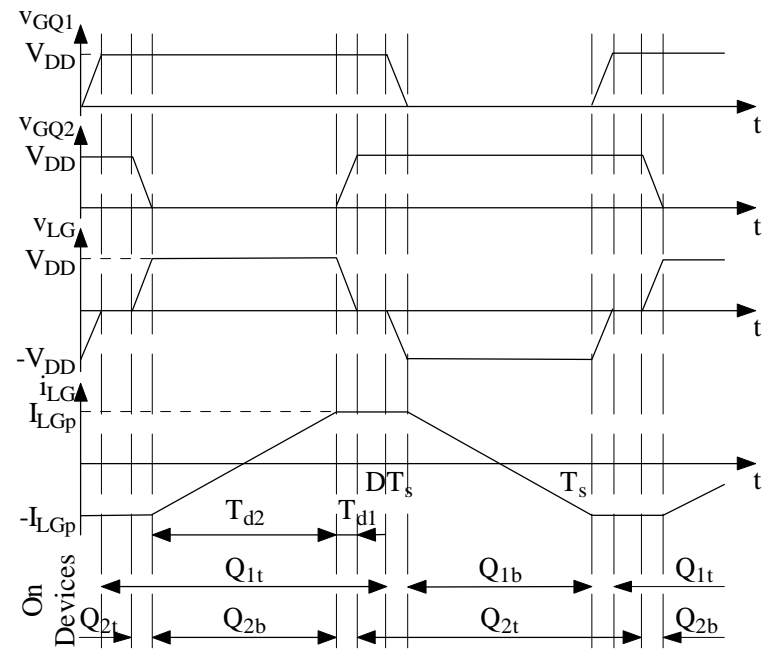

Figure 5. Current and Voltage Waveforms

- The mosfet input capacitance is charged and discharged by the inductor current and $C V^{2}$ loss can be removed.

- A transition time or dead time of $\mathrm{T}_{\mathrm{d} 1}$ exists between the turn on of the two transistors in the totem-pole arrangement in the gate drive circuit and the cross conduction loss can be avoided.

- Both transistors in the gate drive circuit turn on or off at zero voltage or zero current and the switching loss is absent.

If the duty ratio of the mosfets $\mathrm{Q}_{1}$ and $\mathrm{Q}_{2}$ is $\mathrm{D}$, which is larger than 0.5 to ensure that at least one of the mosfets is closed, the dead time ratio $\rho$ can be defined as

$$
\rho=\frac{T_{d 1}}{T_{s}}
$$

Therefore the inductor current linear charging or discharging interval can be easily obtained as

$$
T_{d 2}=(1-D-\rho) T_{s}
$$

Assuming that the input capacitance of the mosfets $Q_{1}$ or $\mathrm{Q}_{2}$ is $\mathrm{C}_{\text {iss }}$, the peak inductor current $\mathrm{I}_{\mathrm{LGp}}$ and the inductance $\mathrm{L}_{\mathrm{G}}$ can be found from the following two equations

$$
I_{L G p}=\frac{C_{i s s} V_{D D} f_{s}}{\rho}
$$




$$
L_{G}=\frac{(1-D-\rho) V_{D D}}{2 I_{L G p} f_{s}}
$$

where $f_{s}$ is the switching frequency and $V_{D D}$ is the drive circuit supply voltage.

Theoretically, the resonant transition gate drive is lossless. However, a small conduction loss still exists in the practical operation due to the following parasitic components:

- The equivalent $\mathrm{AC}$ series resistance $\mathrm{R}_{\mathrm{LG}}$ of the inductor between two mosfet gates,

- The on resistances $\mathrm{R}_{\mathrm{DS}(\mathrm{on}), \mathrm{t}}$ and $\mathrm{R}_{\mathrm{DS}(\mathrm{on}), \mathrm{b}}$ of the top and bottom transistors in the totem-pole,

- The internal gate resistance $\mathrm{R}_{\mathrm{g}}$ of the power mosfet, and

- $C V^{2}$ loss of the transistors in the totem-pole.

Therefore, considering the symmetry of the drive circuit on both sides, total conduction loss in the resonant transition gate drive circuit is

$$
\begin{aligned}
P_{\text {drive }}= & R_{L G} I_{L G, r m s}^{2}+2\left(R_{D S(o n), t} I_{Q 1 t, r m s}^{2}\right. \\
& \left.+R_{D S(\text { on }), b} I_{Q 2 b, r m s}^{2}+R_{g} I_{G 1, r m s}^{2}\right) \\
& +2\left(C_{i s s, Q 1 t}+C_{i s s, Q 1 b}\right) V_{D D}^{2} f_{s}
\end{aligned}
$$

where $\mathrm{I}_{\mathrm{Q} 1 \text { trms }}$ is the RMS current in the top transistor, $\mathrm{I}_{\mathrm{Q} 2 \mathrm{~b}, \mathrm{rms}}$ is the RMS current in the bottom transistor and $\mathrm{I}_{\mathrm{G} 1, \mathrm{rms}}$ is the RMS charging and discharging current flowing through the gate. $\mathrm{C}_{\mathrm{iss}, \mathrm{Q} 1 \mathrm{t}}$ and $\mathrm{C}_{\mathrm{iss}, \mathrm{Q} 1 \mathrm{~b}}$ are respectively the input capacitances of the top and bottom transistors.

If the duty ratio $\mathrm{D}$ is only slightly larger than 0.5 and the zero inductor voltage period in Figure 5 can be ignored, the square of the RMS currents in Equation (5) can be found from the following equations

$$
\begin{gathered}
I_{L G, r m s}^{2}=\frac{1+8 \rho}{3} I_{L G p}^{2} \\
I_{Q 1 t, r m s}^{2}=\frac{1+8 \rho}{6} I_{L G p}^{2} \\
I_{Q 2 b, r m s}^{2}=\frac{1-4 \rho}{6} I_{L G p}^{2} \\
I_{G 1, r m s}^{2}=2 \rho I_{L G p}^{2}
\end{gathered}
$$

It is worth noting that Equations (6) to (9) can also be used to estimate the square of the RMS currents when the transition time intervals $\mathrm{T}_{\mathrm{d} 1}$ of $\mathrm{Q}_{1}$ and $\mathrm{Q}_{2}$ overlap as long as $\rho$ is kept small. Equations (5) to (9) confirm that the power loss in the gate drive circuit is very small if the parasitic resistances are small.

\section{DESIGN CONSIDERATIONS}

The mosfet input capacitance includes gate-to-drain and gate-to-source capacitances. Due to the Miller Effect, the input capacitance is highly non-linear and the total gate charge $Q_{g}$ may be a better parameter in determining the turn on and turn off characteristics of the mosfet, [12]. Consequently, the peak inductor current can be found by the following equation more accurately

$$
I_{L G p}=\frac{Q_{g} f_{s}}{\rho}
$$

In the selection of the transistors in the mosfet gate drive circuit, special attention must be paid to their total gate charges, which must be at least an order of magnitude less than those of the main devices. Apart from being an additional loss term, a fast turn on and turn off of these transistors are required. A quick turn on after the mosfet input capacitance is charged to the supply voltage stops the peak inductor current from flowing through the reverse body diode of the transistors, which may result in higher power loss. Moreover, if the dead time is very short, the turn on and the turn off transition of the transistors must be kept minimal to ensure that two transistors in the totem-pole do not turn on at the same time.

In the operation of the resonant transition gate drive circuit, the mosfet gate charging and discharging currents are not constants as the inductor between two gates resonates with the mosfet input capacitance when both transistors in the totem-pole are turned off. Therefore, the charging and discharging currents follow the sinusoidal waveform and are higher than the peak current at the end of the linear current charging or discharging interval of $\mathrm{L}_{\mathrm{G}}$. Then the actual dead time ratio will be smaller than the preselected value, which is used in Equation (10). If $I_{L G}{ }^{\prime}$ is defined as the average charging and discharging current, Equations (4) and (10) can be rewritten as

$$
\begin{gathered}
L_{G}=\frac{(1-D-\rho) V_{D D}}{2 I_{L G}{ }^{\prime} f_{s}} \\
I_{L G}{ }^{\prime}=\frac{Q_{g} f_{s}}{\rho}
\end{gathered}
$$

Manipulation of Equations (11) and (12) obtains 


$$
\left(\rho-\frac{1-D}{2}\right)^{2}=\frac{(1-D)^{2}}{4}-\frac{2 L_{G} Q_{G} f_{s}^{2}}{V_{D D}}
$$

Equation (13) shows that a larger $\mathrm{L}_{\mathrm{G}}$ leads to a higher dead time ratio $\rho$ as $\rho$ is always kept smaller than $\frac{1-D}{2}$. Therefore, in the design of the gate drive circuit, the inductor can be designed with a slightly larger inductance value than calculated from Equation (4).

In the manufacturing of the resonant transition inductor, Litz wire must be used as the skin depth is $90 \mu \mathrm{m}$ and the proximity effect with $500 \mathrm{kHz}$ current is significant, [13]. Otherwise, the AC resistance of the inductor winding will be unacceptably large and this contributes to a higher inductor loss.

\section{SIMULATION RESULTS}

The simulation is performed with SIMULINK. The power mosfets $Q_{1}$ and $Q_{2}$ are modeled by their input capacitances and four control mosfets are modeled by ideal switches. Several important parameters used in the simulation are listed below:

- Drive circuit supply voltage $V_{D D}=12 \mathrm{~V}$,

- Total gate charge of the mosfet STB50NE10 $Q_{G}=123 n C$,

- Switching frequency $f_{s}=500 \mathrm{kHz}$, duty ratio $D=0.6$ and dead time ratio $\rho=0.1$.

Application of Equations (4) and (10) gives $I_{L G p}=0.615 \mathrm{~A}$ and $L_{G}=5.85 \mu \mathrm{H}$. However, due to the resonance effect in the transition time, the peak inductor current during the transition period is higher than $0.8 \mathrm{~A}$. The input capacitance of the power mosfet is over charged or discharged and an over voltage at the turn on and an under voltage at turn off around $3 \mathrm{~V}$ was seen. A larger inductor of $7.3 \mu \mathrm{H}$ is used in the simulation and the simulation waveforms are shown in Figure 6. They respectively show the gate voltages of $\mathrm{Q}_{1}$ and $\mathrm{Q}_{2}$, the inductor voltage and current waveforms. The simulation waveforms agree well with the waveforms in Figure 5 except that the zero inductor voltage period does not exist in this particular case.

\section{EXPERIMENTAL RESULTS}

Figure 7 shows the experimental waveforms. The key components used in the resonant transition gate drive circuit are:
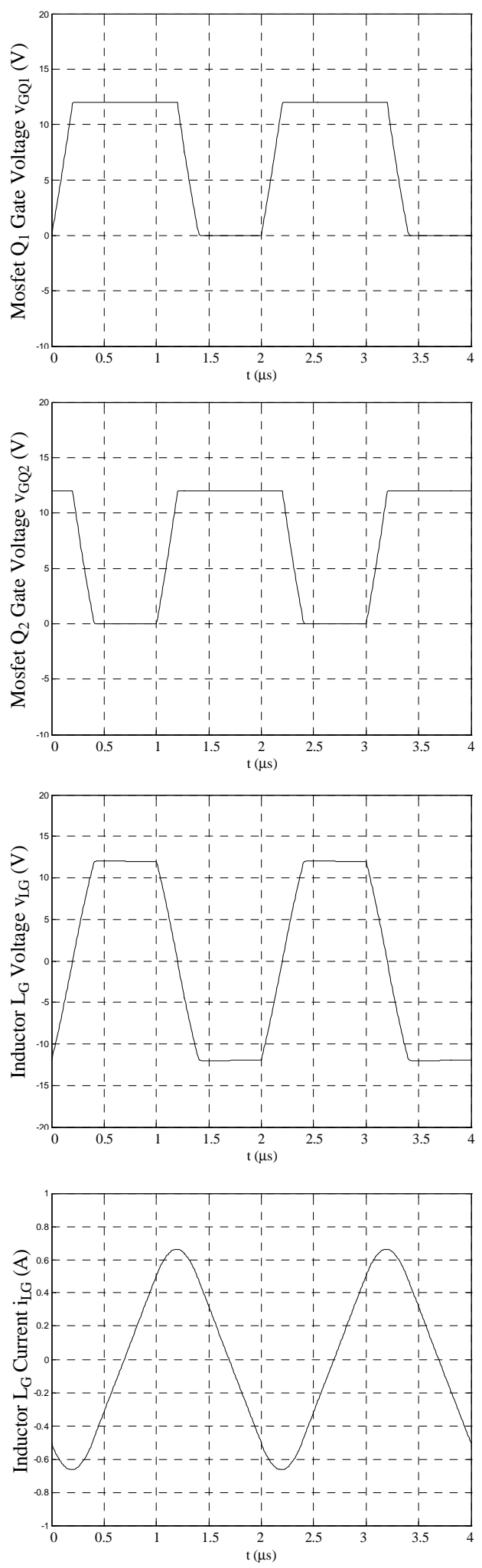

Figure 6. Simulation Waveforms

- High side mosfets in the drive circuit $\mathrm{Q}_{1 \mathrm{t}}$ and $\mathrm{Q}_{2 \mathrm{t}}$ $\mathrm{P}$ channel mosfet IRLML5103, $V_{D S}=-30 \mathrm{~V}$, $I_{D}=-0.76 \mathrm{~A}, R_{D S(o n)}=0.60 \Omega, Q_{g}=3.4 n C$. 


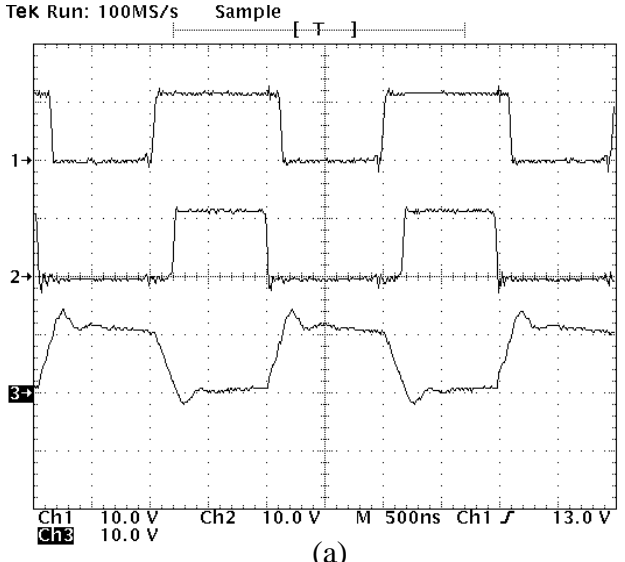

(a)

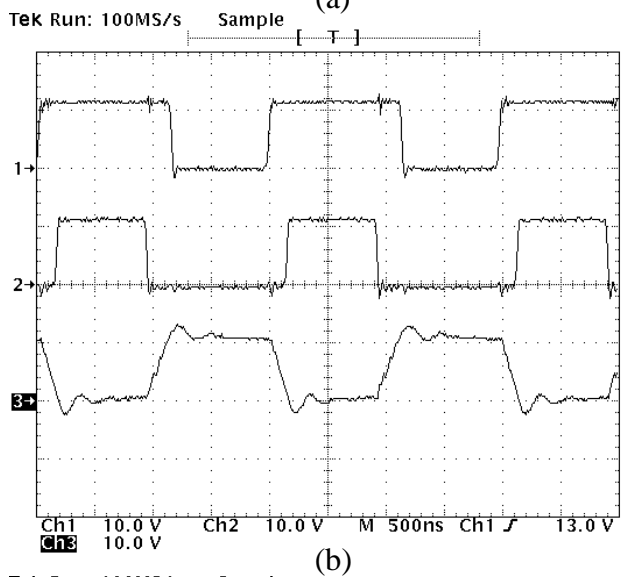

(b)

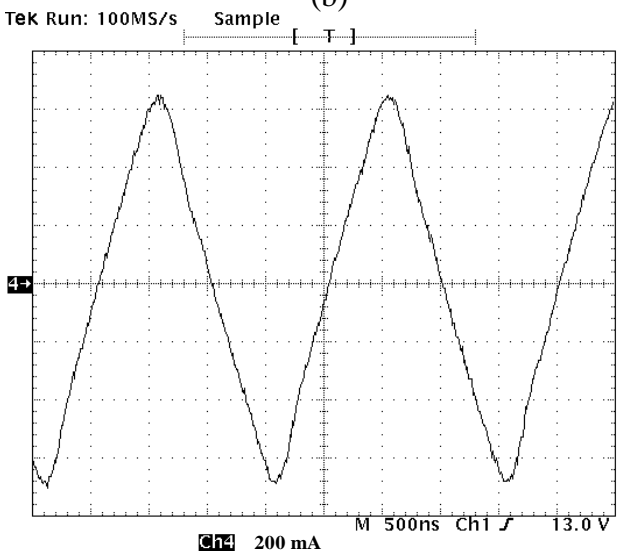

(c)

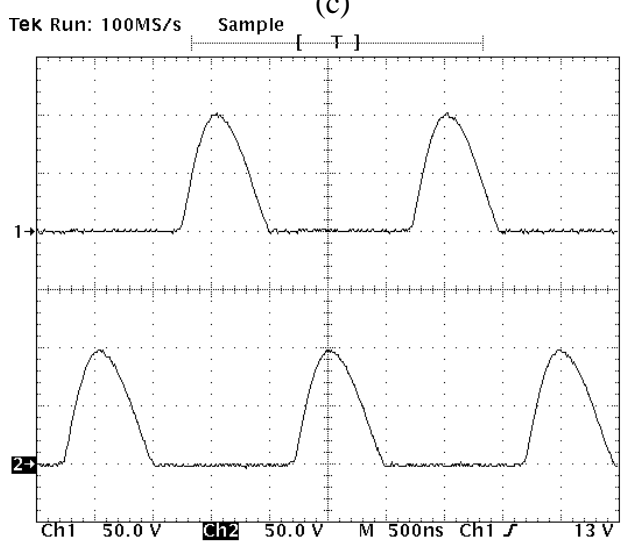

(d)
- Low side mosfets in the drive circuit $\mathrm{Q}_{1 \mathrm{~b}}$ and $\mathrm{Q}_{2 \mathrm{~b}}$ $\mathrm{N}$ channel mosfet IRLML2803, $V_{D S}=30 \mathrm{~V}$, $I_{D}=1.2 \mathrm{~A}, R_{D S(\text { on })}=0.25 \Omega, Q_{g}=3.3 n C$.

- Inductor between the power mosfet gates $\mathrm{L}_{\mathrm{G}}-$ $6.98 \mu \mathrm{H}$. Core type: Philips ETD44 gapped. Ferrite grade: Philips 3F3. Litz wire: 34 strands of $110 \mu \mathrm{m}$ diameter wire.

The experimental waveforms match well with the simulation waveforms. Figure 7(a) shows the gate waveforms of $\mathrm{Q}_{1 \mathrm{t}}, \mathrm{Q}_{1 \mathrm{~b}}$ and $\mathrm{Q}_{1}$ from top to bottom. Figure 7(b) shows the gate waveforms of $\mathrm{Q}_{2 \mathrm{t}}, \mathrm{Q}_{2 \mathrm{~b}}$ and $\mathrm{Q}_{2}$ from top to bottom. After turn on of the transistors in the gate drive circuit, an over voltage or under voltage appears on the gate waveforms of $\mathrm{Q}_{1}$ and $\mathrm{Q}_{2}$. This is caused by the voltage drop across the embedded reverse body diodes of the transistors. Figure 7(c) shows the current waveform in the inductor between the gates. When one of the power mosfets $Q_{1}$ and $Q_{2}$ is fully on and the other is fully off, the current linearly increases or decreases as explained in Figure 5. Figure 7(d) shows the drain source voltage waveforms of $\mathrm{Q}_{1}$ and $\mathrm{Q}_{2}$ respectively. The waveforms confirm that two power mosfets $\mathrm{Q}_{1}$ and $\mathrm{Q}_{2}$ turn on at zero voltage.

The power consumption in the resonant transition gate drive circuit is compared with the conventional gate drive circuit, as shown in Table 1.

\begin{tabular}{|c|c|c|}
\hline Power & $\begin{array}{c}\text { Resonant } \\
\text { Transition Gate } \\
\text { Drive Circuit }\end{array}$ & $\begin{array}{c}\text { Conventional } \\
\text { Gate Drive } \\
\text { Circuit }\end{array}$ \\
\hline $\begin{array}{c}\text { Control } \\
\text { Signal } \\
\text { Generation }\end{array}$ & 0.66 & 0.72 \\
\hline $\begin{array}{c}\text { Mosfet } \\
\text { Driving }\end{array}$ & 0.72 & 2.75 \\
\hline Total $(\mathbf{W})$ & $\mathbf{1 . 3 8}$ & $\mathbf{3 . 4 7}$ \\
\hline
\end{tabular}

Table 1. Power Consumption in Two Drive Circuits

A power loss breakdown calculation for the mosfet driving loss in the resonant transition gate drive circuit is given in Table 2. The calculated total power loss $0.57 \mathrm{~W}$ agrees favourably with the mosfet driving power loss in the experiment.

\begin{tabular}{|c|c|}
\hline Component & Power \\
\hline Inductor Loss & 0.22 \\
\hline Control Mosfets Conduction Loss & 0.15 \\
\hline Power Mosfet Gate Resistance Loss & 0.12 \\
\hline Control Mosfets Driving Loss & 0.08 \\
\hline Total (W) & $\mathbf{0 . 5 7}$ \\
\hline
\end{tabular}

Table 2. Power Loss Breakdown

Figure 7. Experimental Waveforms 
The inductor used in the drive circuit is relatively large compared with the control mosfets. Miniature PCB mount axial inductors with high quality factor were also attempted. This type of inductor has a body length of $10 \mathrm{~mm}$ and diameter of $4 \mathrm{~mm}$. Two $1 \mu \mathrm{H}$ and one $4.7 \mu \mathrm{H}$ axial inductors are series connected in the drive circuit and the experiment showed a slightly higher drive power of $0.83 \mathrm{~W}$.

The control signals in both of the drive circuits are generated by the analogue circuitry and an effort was made to limit the power consumption to the level seen in the traditional design. As the two transistors in the totem-pole of the resonant transition gate drive circuit require separate driving signals, the control is more complex. However, the new drive circuit requires only $0.72 \mathrm{~W}$ to drive four control mosfets and two power mosfets, which is less than the conventional gate drive circuit. A total power of more than $2 \mathrm{~W}$ is saved in the new mosfet gate drive circuit, which improves the efficiency by at least $2 \%$ for a $100-$ Watt converter.

\section{CONCLUSIONS}

In this paper, the possible loss mechanisms of the conventional gate drive circuit are analysed and the resonant transition gate drive circuit for the half bridge dual converter is proposed. The new drive circuit is able to remove all power losses related to the conventional drive circuit. Explicit design equations have been established and the power losses in the new drive circuit due to the parasitic effects have been studied in detail. Both of the simulation and experimental results validate the theoretical analysis and it can be shown that more than $2 \mathrm{~W}$ are saved in driving the control and power mosfets in the new drive circuit.

Compared with the other resonant gate drive circuits proposed previously, the number of components in the resonant transition gate drive circuit for the half bridge dual converter does not cause a significant increase. Only one small inductor is added and it is ready for semiconductor integration. It is believed that further power reduction in the new drive circuit can be achieved if microprocessors or digital circuits are used to generate the control signal waveforms.

\section{REFERENCES}

[1] Q. Li and P. Wolfs, "A Resonant Half Bridge Dual Converter," Proc. Australasian Universities Power Engineering Conference, 2001, pp. 263268, also Journal of Electrical \& Electronic
Engineering Australia, Vol. 22, No. 1, pp.17-23, 2002.

[2] S. H. Weinberg, "A Novel Lossless Resonant MOSFET Driver," Proc. IEEE Power Electronics Specialists Conference, 1992, pp. $1003-1010$.

[3] Q. Li, "Development of High Frequency Power Conversion Technologies for Grid Interactive PV Systems," Master of Engineering Dissertation, Central Queensland University, Australia, 2002.

[4] J. Qian and G. Bruning, "2.65 MHz High Efficiency Soft-Switching Power Amplifier System," Proc. IEEE Power Electronics Specialists Conference, 1999, pp. 370-375.

[5] W. A. Tabisz, P. Gradzki and F.C. Lee, "ZeroVoltage-Switched Quasi-Resonant Buck and Flyback Converter - Experimental Results at 10 MHz," Proc. IEEE Power Electronics Specialists Conference, 1987, pp. 404-413, also IEEE Trans. Power Electron., Vol. 4, No. 2, pp. 194-204, Apr. 1989.

[6] Turbodriver-000 Datasheet, Turbo Switchers (http://www.turboswitchers.com), Sept. 2001.

[7] J. Diaz, M. A. Perez, F. M. Linera and F. Aldana, "A New Lossless Power MOSFET Driver Based on Simple DC/DC Converters," Proc. IEEE Power Electronics Specialists Conference, 1995, pp. 37-43.

[8] Y. Chen, F. C. Lee, L. Amoroso and H. Wu, "A Resonant MOSFET Gate Driver with Complete Energy Recovery," Proc. The Third International Power Electronics and Motion Control Conference, 2000, pp. 402-406.

[9] K. Yao and F. C. Lee, "A Novel Resonant Gate Driver for High Frequency Synchronous Buck Converters," Proc. Applied Power Electronics Conference and Exposition, 2001, pp. 280-286, also IEEE Trans. Power Electron., Vol. 17, No. 2, pp. 180-186, Mar. 2002.

[10] D. Maksimovic, "A MOS Gate Drive with Resonant Transitions," Proc. IEEE Power Electronics Specialists Conference, 1991, pp. 527 $-532$.

[11] T. López, G. Sauerlaender, T. Duerbaum and T. Tolle, "A Detailed Analysis of a Resonant Gate Driver for PWM Applications," Proc. Applied Power Electronics Conference and Exposition, 2003, pp. 873-878.

[12] K. J. Christoph, D. M. Bernero, D. J. Shortt and B. J. Lamb, "High Frequency Power MOSFET Gate Drive Considerations," Proc. International High Frequency Power Conference, 1988, pp.173-180.

[13] E. C. Snelling, Soft Ferrites, Properties and Applications. London: Butterworths, 1988. 